\title{
Research on the Philosophy of "Social Quality Management" in China-- A Summary of the Innovation of Social Quality Management Theory
}

\author{
Yabin Li ${ }^{1, a}$, Yanan Liu ${ }^{2, b}$ \\ ${ }^{1}$ School of Business, Xi 'an Siyuan University, Xi 'an 710038, P.R.China; \\ ${ }^{2} \mathrm{Xi}$ 'an Institute of Optical and Precision Mechanics, CAS, Xi 'an, 710068, P.R.China \\ a9986984184@qq.com, b354809308@qq.com
}

Keywords: Total quality management; social quality management; quality management stage; social quality

\begin{abstract}
The concept of social quality management was first proposed by Chinese quality scholars in the world in the 1980s. Over the past 30 years, social quality management has continued to be researched and developed despite its slow progress. This article outlines the emergence and development of the concept of social quality management in China in the past three decades, analyzes the background of social quality management and the environmental changes and outlines the challenges that contemporary quality management is facing. The paper analyzes the phenomenon of "technical failure" and the characteristics of "social attributes of quality" in the internal and external environment of contemporary enterprises. Finally, it describes the concept and main features of the new social quality management, and discusses the theory of social quality management--that quality management will enter a new stage of social quality management.
\end{abstract}

\section{Research background}

Quality management is one of the most active disciplines in the field of management in the world today. The theoretical research and practical application of quality management in the 20th century have been extensively and deeply developed. After 100 years of quality management theory has passed the quality inspection stage, the statistical quality control Stage and total quality management stage of the development process. In the past two or three decades, the development of world science and technology, the advancement of production technology, the formation of global market competition and the pursuit of perfection quality have made quality an important part of corporate strategy and national strategy.

In the 21st century, along with the advent of the Internet age, the rapid development of new technologies and the transformation of modern production organization and management methods, people are obliged to seek new and more effective quality management methods for providing high-quality products and services. On the other hand, with the rapid changes in the market and the intensified competition in modern social life, fake and shoddy products, unfair competition, infringement of consumers' rights and interests, major and serious malignant quality and safety incidents have occurred from time to time, the social conscience of commercial organizations has been extinct, and the lack of social morality , Mercenary, etc. have become the new topics that quality management has to consider and face. At the same time, human society faces a series of global problems such as the deterioration of the ecological environment and the destruction of resources in the process of its development. Governments and many sociologists have come up with the concept of sustainable development, green development, building a harmonious society and creating an ecological society. This objectively requires people to understand what quality is, what the quality we need is, and how we can achieve that quality we need [1].

The new environment and new problems mentioned above that quality and quality management now face, lead to the rethinking and understanding of the problems of quality and quality 
management and the innovative appeal of the theory of quality management. Developed countries in the world are seeking new methods and theories of quality management.

The concepts and ideas of social quality management, which originated in China in the 1980s, provide a new research direction for solving the predicament of real-quality social problems and innovating the methods of quality management with its unique ideas and theoretical perspectives.

\section{The emergence and development of the concept of "social quality management" in China}

\subsection{The Emergence of the Concept of "Social Quality Management" in China}

The concept and thought of social quality management originated from China after the reform and opening up. In the published literature, the concept of social quality management first appeared in the article "Standardization and Quality Management" No. 10 Chen Jian Nan - The introduction of the concept of "social quality management" in 1985. In this essay, Mr. Chen pointed out: The concept of "social quality management" is an important feature of our country's quality management in the future and is the continuation and development of the concept of "total quality management." It makes quality management jump out of the scope of a single enterprise, seize the key to promote the improvement of product quality in our country, with social quality management to promote the quality management of enterprises. Solidly improve the quality of enterprise management, so that China's quality management to a new level [2].

In this paper, Mr. Chen gives a definition of social quality management. "Social quality management" is defined as: with the entire community members as the owner of the product quality and service quality, with the quality management authority as the center, to establish a set of assurance systems for social product quality and service quality, social quality management agencies and each member of the community give full play to the product quality and service quality by supervision, management and dominance, and promote enterprises and service departments to improve product quality and service quality. To provide the community satisfied with the quality of products and services.

Liu Jingkang and Liu Ning (1992) put forward the concept of " the whole society's quality management " in the paper entitled Forwarding to the whole society's quality management. The term " the whole society's quality management " refers to the concept of " A comprehensive quality management system that participates in the entire process of production, distribution and consumption of products by producers, operators, managers and consumers. The article believes that the quality management of the whole society is characterized by the development of productive forces. The requirements of the development of productive forces make quality management develop from the quality inspection stage to the statistic quality management stage and then to the total quality management stage. The new technological revolution has greatly increased the socialization of production in the enterprises so that quality management has also entered a new stage, namely "the stage of the whole society's quality management in " [3].

The second issue of Journal of Xi'an Petroleum Institute (Social Science Edition) in 1997 published a paper entitled On "Social Quality Management" by Professor Sun Bo-nian. Under the background of establishing and developing the socialist market economy and deepening the opening up to the outside world, this paper puts forward some suggestions on how to strengthen the quality management and improve the product quality. The article points out that it is not enough to rely on the enterprise for the quality control and guarantee, and the quality management should be raised to the level of "social quality management". Quality management is a social responsibility, to mobilize all sectors of society to participate in the power, and to promote the quality management theory and practice to a new stage [4]. The authors believe that the content of total quality management can no longer meet the needs of the development and the needs of the social situation, and call for social quality management to be involved in all national quality management activities. The article argues it is necessary to improve the total quality management in the following three aspects: 1 . The sociality of quality management; 2 . The social governance of quality management, that is, social 
responsibility; 3. Improving the market mechanism.

\subsection{The Development of "Social Quality Management" concept in China}

At the turn of the century, the concept of social quality management has been continuously nurtured and developed in China. New concepts, such as "social quality management stage", "social quality idea", " the whole society's quality management " and "macro quality management" appeared one after another.

After entering the 21st century, the idea of social quality management in China has a certain recognition and basis, the "social quality management stage" formulation has appeared in some colleges and universities teaching materials and papers.

Currently available information, first put forward the concept of "social quality management stage" is 1998, edited by Professor Zhang Gongxu "Quality Management". The book makes it clear that: After entering the 21st century, quality management will enter a new stage of development, the fourth stage, which we call the Social Quality Management (SQM) stage [5].

Later, in other colleges and universities teaching materials, the thesis of social quality management stage is also appeared, edited by Professor Zong Yun Zhang(2003) the "quality management" proposed that the quality management will enter the fourth stage of development social quality management stage. The main understanding of social quality management phase is based on the following: In the 21st century, not only the scale of quality management will be greater, but more importantly, quality as one of the important factor of social elements - politics, economy, science and technology, culture, quality and natural environment develops. This means that the quality will be subject to the political, economic, technological, cultural, and natural environment simultaneously. The quality system will develop as a subsystem in a larger social system. Therefore, the 21st century will bring quality management to a new stage of development, the fourth stage, which we call the stage of social quality management [6].

January 23, 2010 China Construction Daily published a reporter Zhai Li entitled "Supervision industry to establish the concept of social quality." the article elaborates the idea of the concept of social quality first proposed by Zhang Qinglin, president of China Construction Supervision Association.

This article defines "the idea of social quality" as follows: social quality is to take responsibility for the state, responsibility to the people and responsibility to the history as the soul of the quality management of engineering construction, that is, Taking the social responsibility as the core point of view, taking the project quality and striving for high-quality projects as the basic requirements, taking the scientific management of construction projects as the basic method, the collection of the theory and practice of quality management integrating the construction project quality concepts, systems and methods [7].

In 2009, macroscopic quality management, a monograph entitled Prof. Cheng Hong of Wuhan University, put forward a macroscopic quality management system from the perspectives of government and social forces on the supervision and management of quality. It emphasizes the importance of the social management function of quality management and the improvement of social quality management system. The article believes that the government regulation of quality, especially for the management of the above new overall quality phenomenon, more needs is the implementation of macroeconomic management theory. Therefore, to study the macroscopic quality management is necessary for the development of the existing quality theory and also necessary for a scientific explanation of the new overall quality phenomenon. It is also necessary for optimizing the government's quality control [8].

To sum up, from the introduction of the concept of "social quality management" at the end of the last century to the appearance of the concepts of "social quality management stage", "social quality idea", " the whole society's quality management " and "macro quality management" in the new century, shows that people's understanding of the concept of social quality management further developed and is more widely recognized. At the same time, it also shows that, in the process of establishing, developing and perfecting the socialist market economy in China, in the context of the 
challenges of economic globalization in the new century and under the background of the rising demands for international sustainable development, People's new understanding and expectation of the progress and development of quality management has an important role to play.

\section{Developed countries on the quality management theory innovation}

At present, the overseas quality circles have not put forward mature concepts and clear theoretical directions in quality management innovation. However, they have expressed their strong expectations and wishes for changing the status quo of quality management and meeting the new future of quality management. In recent years, quality experts from the United States and Australia have proposed the concepts of "Quality 3.0" and "Quality 3G" respectively (Kreg Kukor, 2010; N. Grigg, 2011).

\subsection{Australia's "3G Quality" point of view}

At the 2010 Australian-New Zealand Quality Management Conference, Professor Kevin Forley, Chairman of the Australian Quality Organization, presented the concept of "3G Quality Management." In the concept of 3G quality taught by Professor Kevin Forley, the 30s and 60s of the last century is called the era of statistical quality control is the first generation. The 1970s and the end of the last century are referred to as the era of total quality management, Second generation; from the 21st century to the third generation. The text does not make a clear definition of the characteristics of the third generation of quality management, but that the main features of 3G quality management are the following:

- Customer is only one stakeholder, not the only stakeholder;

- A clear quality management theory;

- A significant difference for quality management as a whole organization's strategy between as theory and tools;

- Clearly identify organizations as part of society;

- Customer satisfaction through product and service quality is a means, not an end, [9].

From these points of view, we can see that in today's world, there is a unanimous understanding and recognition of the future development of quality management.

\subsection{Americans expect - "Quality 3.0"}

United States "Quality Progress" No.2 2010, entitled "Quality 3.0 is the next stage of evolution at hand?" Article. The article is the author of Kreg Kukor and two quality industry president talk. The conversation focused on the current direction of quality management, the improvement of sustainable quality, and what they think about what Quality 3.0 will bring to us.

As can be seen from the title of the article, Americans hope that "Quality 3.0" can become an effective solution to new quality problems in an era of globalization. What is referred to as "quality 3.0"? This article does not give a clear description, may be a quality management software system, may also be a new quality management system.

Based on the perspectives of the two CEOs of multinational corporations in the United States, this article analyzes the new challenges that the US quality industry faces to the current quality management, expresses their dissatisfaction with the current stagnation of quality management, Expectations of quality innovation or new quality revolution and prediction of future breakthroughs in quality management.

\section{Connotation and basic ideas of social quality management concepts}

\subsection{New Concept of "Social Quality Management"}

Now we give the definition of SQM comparing with a definition of TQM.

Total Quality Management (TQM) is defined as: " A management approach of an organisation centered on quality, based on the participation of all its members and aiming at long term success 
through customer satisfaction and benefits to all members of the organisation and society." ISO 9000:2005 [8].

The definition of social quality management (SQM): With social organizations as the mainstay, social needs as the center, based on the need to meet the needs of social development and progress, including the government, the public, industry and the organization itself, and other relevant parties involved in order to achieve their products and services to achieve customer satisfaction and other All stakeholders involved in the interests of a sustainable performance management system.

The concept of social quality management (SQM), compared with the concept of total quality management, has undergone profound changes in the following aspects:

\section{a. The implementation of the main of quality management has changed.}

In the total quality management stage, the main body of quality management is a specific organization. Specific organizations carry out related quality management activities from the perspective of their own business and business purposes; the objects and scope of their quality management activities are mainly carried out within the organization itself. The social quality management believes that quality management is more emphasized in the community as a whole to implement. A specific organization must regard itself as a member of the entire social organization system and form a harmonious and balanced relationship with the government regulation and social interests.

\section{b. The goal of quality management has changed.}

The ultimate goal of quality management is no longer the customer's needs, but the social needs; no longer just customers, but the whole society. The concept of quality of products and services, customer-centric, is increasingly challenged by all sectors of society. Corporate organization has become a micro-social form of modern society. The relationship between business organizations and society is more and more related and close. The economic interests and rights of the owners of enterprises are more and more restricted by the interests and power of society as a whole. On the one hand, they show the social attributes of the ultimate goal of quality management, Social Attributes of Economic Benefits. Enterprises to assume social responsibility and establish a sense of social quality, should be the basic concepts and business quality strategy for the long-term business to follow.

\section{c. Quality management behavior will change.}

The organization's business activities include the purpose of the act, the course of the act, and the result of the act. At the stage of total quality management, the focus of quality management activities is mainly the result of behavior. Social quality management requires that the attention should be paid to the behavior process while paying the same attention to the result of enterprise behavior. For example, intensiveness of production and operation, environmental protection, safety, intermediate products (by-products) and so on.

\subsection{The concept of "social quality"}

ISO defines quality as: "Quality: the degree to which a set of intrinsic characteristics meets the requirements" (ISO 9000: 2005). "Social quality" can be defined as the overall performance of the organization's behavior processes and outcomes that meets the needs of society.

Based on the above definition, the main new characteristics of the concept of "social quality" compared with the concept of "quality" in TQM are as follows: (1) quality is not only reflected in the result of economic activities, but also in the process of economic activities; (2) it is beyond the concept of meeting customer requirements, to the pursuit of social needs for the purpose; (3) It is a comprehensive quality performance, including the further expansion of the quality characteristics. In the continuous development of quality management theory and practice for more than 100 years, the concept of quality has undergone a historical process of continuous development and deepening. People's understanding of the concept of quality reflects the history of the evolution and development of quality management theory. 


\section{Conclusion}

The concepts and ideas of social quality management proposed by Chinese quality scholars are rooted in the historical background of China's remarkable economic and social reform. It is a quality management theory with Chinese characteristics created by China over the past 40 years under the historical conditions of rapid economic development and management.

Social quality management will be the quality of all social organizations for the common purpose of society, to assume its social responsibility quality obligations. Establishing the idea of social quality management not only sets new requirements for the enterprises, but also puts forward new requirements to the government on how to guide and supervise the enterprises and how to innovate the macro management mechanism of social quality management. This emerging area has yet to attract more attention and further research by management and academia.

The concept and thought of social quality management will promote the innovation of quality management methods in an all-round way and bring a new quality management revolution. This revolutionary change in quality management will surely be reflected in future practice. Although there are no successful cases to provide a clear solution for everyone, it is indeed a new topic for all quality practitioners and managers. We expect to discuss and explore together with more quality management scholars and researchers around the world.

\section{References:}

[1] Li Yabin, "A Brief Introduction to International Quality Maturity Model" and Its Structure [J]. World Standardization \& Quality Management, 2007 (3) 52-54.

[2] Chen Jiannan. The introduction of the concept of "social quality management" [J]. Standardization and Quality Management, 1985 (10) 20-22.

[3] Liu Jingkang, Liu Ning. Forwarding to the whole society's quality management [J]. Technology Management Research, 1992 (6) 36-38.

[4] Sun Bo-nian. On "social quality management" [J]. Journal of Xi'an Petroleum University (Social Science Edition), 1997 (2) 53 56.

[5] Zhang gongxu. Quality Management [M]. Beijing: China Financial and Economic Publishing House, 1998.

[6] Zong Yun Zhang, Tian Haifeng, Wang Shaofeng. Quality Management [M]. Beijing: Higher Education Press, 2003.

[7] Zhai Li. Supervision industry to establish the concept of social quality [N]. China Construction News, Jan. 23. 2010.

[8] Cheng Hong. Macro Quality Management [M]. Wuhan: Hubei People's Publishing, 2009.

[9] N. Grigg 3G ... Quality for the future New Zealand Quality 2011 (2).

[10]Kreg Kukor. Quality 3.0 is the next stage of evolution at hand? Quality Progress. 2010 (2) 41.

[11]SO 9000: 2005.Quality Management Systems - Fundamentals and Vocabulary [S]. 